(C) 2016 IEEE. Personal use of this material is permitted. Permission from IEEE must be obtained for all other uses, in any current or future media, including reprinting/republishing this material for advertising or promotional purposes, creating new collective works, for resale or redistribution to servers or lists, or reuse of any copyrighted component of this work in other works. 


\section{A Review on the Virtual Power Plant: Components and Operation Systems}

\author{
Sahand Ghavidel and Li Li \\ Faculty of Engineering and \\ Information Technology, \\ University of Technology, \\ Sydney, PO Box 123, Broadway, \\ NSW 2007, Australia \\ \{sahand.ghavideljirsaraie, \\ li.li\}@uts.edu.au
}

\author{
Jamshid Aghaei \\ Department of Electronics and \\ Electrical Engineering, Shiraz \\ University of Technology, \\ Shiraz, Iran \\ aghaei@sutech.ac.ir
}

\author{
Tao $\mathrm{Yu}$ \\ College of Electric Power, \\ South China University of \\ Technology, Guangzhou, \\ 510640, China \\ taoyu1@scut.edu.cn
}

\author{
Jianguo Zhu \\ Faculty of Engineering and \\ Information Technology, \\ University of Technology, \\ Sydney, PO Box 123, Broadway, \\ NSW 2007, Australia \\ jianguo.zhu@uts.edu.au
}

\begin{abstract}
Due to the high penetration of Distributed Generations (DGs) in the network and the presently involving competition in all electrical energy markets, Virtual Power Plant (VPP) as a new concept has come into view, with the intention of dealing with the increasing number of DGs in the system and handling effectively the competition in the electricity markets. This paper reviews the VPP in terms of components and operation systems. VPP fundamentally is composed of a number of DGs including conventional dispatchable power plants and intermittent generating units along with possible flexible loads and storage units. In this paper, these components are described in an all-inclusive manner, and some of the most important ones are pointed out. In addition, the most important anticipated outcomes of the two types of VPP, Commercial VPP (CVPP) and Technical VPP (TVPP), are presented in detail. Furthermore, the important literature associated with Combined Heat and Power (CHP) based VPP, VPP components and modeling, VPP with Demand Response (DR), VPP bidding strategy, and participation of VPP in electricity markets are briefly classified and discussed in this paper.
\end{abstract}

Index Terms - Virtual Power Plants, CHP, Demand Response, Combined Heat and Power, Distributed Generations.

\section{INTRODUCTION}

$\mathrm{D}$ espite the fact that DGs have the capability of substituting the energy generated by conventional power plants, they require advanced technologies to safely and economically deliver energy to the system. With the high penetration of DGs, this passive attitude always causes the increasing total investment on the infrastructure and, in the long run, has an impact on the DG integration $[1,2]$. In order to find a solution to the mentioned issue, DGs must be incorporated by an active systematic arrangement which helps them to contribute simultaneously in different electricity markets. Virtual Power Plant (VPP) is a conception that can be employed in accomplishing this objective [2]. Many projects have been done using VPP concepts, for example, the European virtual fuel cell power plant [3], and the FENIX VPP [4].

The VPP aggregates many heterogeneous Distributed
Energy Resources (DERs) to function as a single DER. It also has the inherent capacity to include the influence of the system on the aggregated DER output. In order to participate in the electricity market, the VPPs have nondispatchable and dispatchable power plants including renewable and nonrenewable ones, storage units such as batteries and pump storage, and responsive loads that have some flexibility in their consumption energy levels. In other words, in VPPs, there are diverse kinds of power plants and storage units combined to overcome and handle the stochastic nature of renewable generators, the energy price and so on in a coordinating attitude [2]. VPP consists of two categories, the commercial VPP (CVPP) and technical VPP (TVPP). Fundamental and most important functions of CVPP are to optimize and schedule the production of aggregated DER units and consumption of the aggregated Demand Response (DR) resources. These functions are generally based on submitting DERs' characteristics, predicting the production and energy consumption, forming offers or bids, submitting bids or offers to different electricity markets, calculating optimal production and consumption, and making a daily schedule, etc. On the other hand, the TVPP, which is defined comprehensively in [5], takes into consideration the actual system impact on the DER aggregated profile in addition to the cost and operating characteristics of the portfolio. The TVPP is composed of DERs which are located at the same geographical site. The most important tasks of the TVPP are uninterrupted monitoring, managing of financial issues, fault detection and localization, and so on [6].

The rest of the paper is organized as follows. Firstly, the VPP components including the conventional dispatchable power plants, intermittent generating units, storage units and flexible loads are described individually, and the literature related to them is briefly introduced. In the energy production units section, different literature related to control methods and procedure of CHP-based VPPs is provided. In storage units section, the literature related to electric vehicles as energy storage units in VPPs is reviewed. Finally, the operation system of the VPP with its related literature is presented. 


\section{VPP COMPONENTS}

There is some substantial literature that studied the different works in the areas of modeling such as modeling of DERs, storage units and other related components in a VPP. In what follows, firstly the VPP components are described, and then the most important literature related to them is briefly introduced.

VPP basically has three effective components. The first important component includes the conventional dispatchable power plants which are usually small scale fossil fuel power stations, and intermittent generating units. The second component includes the storage units which store electrical energy at a specified time in order to use it in the future. The third component includes the responsive or flexible loads which basically encompass residential housing and industrial electrical energy.

Different components and strategies are used in literature for VPPs; for example in [7], the VPP system consists of wind, solar, hydrogen and thermal units. In this study, the intermittent resources of the VPP are the wind and solar generating station units. Ref. [8] considers a VPP consisting of DGs, electric vehicles and capacitors. Ref. [9] studies a VPP which is equipped with intermittent and conventional power plants including renewable sources and storage units. In [10], a VPP which includes wind generation units as an intermittent source, pumps storage system as a storage facility, and a conventional dispatchable power plant is scheduled. Ref. [11] studies the typical VPP configuration and establishes a VPP with small generators including the wind, solar, CHP plants and flexible loads. In [12], a VPP including solar units and responsive demands is explored. Ref. [13] studies a CVPP which includes DERs, battery storage units, and flexible loads. Ref. [14] considers a VPP as the combination of wind power units along with electric vehicles. Ref. [15] suggests a procedure to create a VPP including a wind generator and a DR provider. A VPP with wind generation units and pumped storage unit station working in a remote and isolated island is studied in [16].

In the following subsections, different components of VPP are defined in detail, and the related recent literature is briefly described.

\section{A. Energy Production Units (dispatchable power plants and intermittent generating units)}

Gas turbines, diesel generators, and biodiesel or biogas resource based generators are some of the examples of conventional dispatchable power plants that are used in a VPP.

Nowadays, with rapidly increasing integration of renewable energy resources, they are an essential part of a VPP. These kinds of energy resources are intermittent and have stochastic inputs. In other words, their output comes from energy sources that generally depend on natural resources such as the wind or the sunlight. As a consequence of the mentioned phenomena, the output of these kinds of stochastic generating units is naturally hard to predict. In addition, these stochastic generating units are nondispatchable. Therefore, they need to be provided with backup units such as conventional dispatchable power plants and storage units.

Besides, using an electrical generating station for providing electricity and heat together as CHP units is also very attractive and popular in a VPP. The CHP concept, in particular, has the best thermal unit's efficiency. Also, in the direction of making an adjustment for the imbalance and likely financial disadvantages, the CHP is used to prevent the system from financial risks. For example, in [17], the capability of a VPP that includes CHP and solar units facilities is assessed to reduce the imbalance between the power generation and consumption due to the renewable generations. In this study, the VPP is willing to contract to make energy bids into the markets including the day-ahead and balancing markets. The balancing market alleviates the energy imbalance due to the difference between the expected value of the predicted electricity and the actual output. The CHP is used for adjusting this imbalance.

Different control methods and procedure can be used for CHP-based VPPs. For example, a decentralized control method is explored in [18] for optimizing the residential systems including CHPs, heating boilers and a thermal storage. In [18, 19], the most desirable procedure of CHP arrangements is clearly characterized. Ref. [20] demonstrates a system to assess the most desirable bidding planning of a VPP consisting of a CHP coupled with district heating ( $\mathrm{CHP}$ $\mathrm{DH})$. In this paper, the ultimate goal is to scientifically investigate a bidding strategy for a VPP with maximum benefits. In [21], a stochastic profit-based model is taken into consideration for scheduling purposes specifically designed for an industrial customer with CHP units in which the consumer requirements are provided by a responsive load.

A modeling methodology for CHP systems is presented in [22] as an element of the VPP with a high penetration of renewable energy resources. The operational schemes of $\mathrm{CHP}$ systems are demonstrated in connection with the market.

\section{B. Storage Units}

Storage units provide an opportunity for a VPP to transfer electrical energy from one period of time to another. The most important purpose of using storage units is to utilize this energy at a future time. Nowadays, in the production systems where stochastic renewable generators are used, the storage units are taken into consideration to balance the demand and generation. Ref. [23] reviews the storage units technologies used with stochastic renewable generators. 


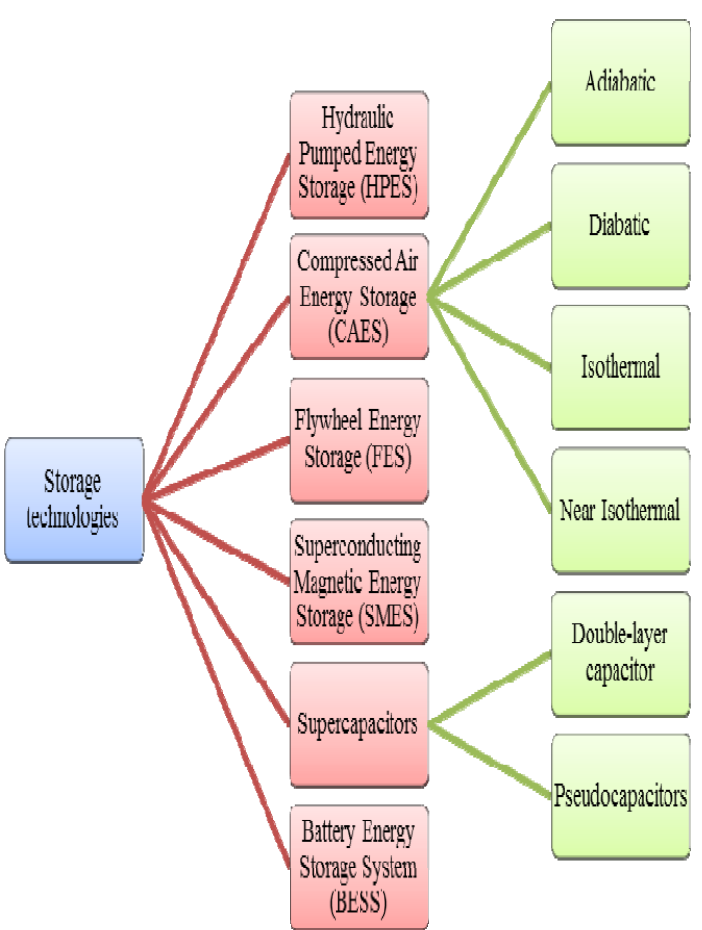

Fig. 1. Storage technologies that can be combined with the VPP

There are many types of storage units that can be used in the modern VPP. The most important storage units that can be combined with the VPP are Hydraulic Pumped Energy Storage (HPES) which is a sort of hydroelectric energy storage used for balancing load, Compressed Air Energy Storage (CAES) which is one way to store energy using compressed air, Flywheel Energy Storage (FES) which works by speeding up a rotor to an exceedingly high speed and preserving the produced energy for use at another time, Superconducting Magnetic Energy Storage (SMES) systems which accumulate energy in the magnetic field generated by the flow of direct current in a superconducting coil, Electric double-layer capacitors (EDLC), Battery Energy Storage System (BESS), and so on. Ref. [24] reviews the HPES capabilities, technical progress, and hybrid systems as windhydro, pv-hydro, and wind-pv-hydro. Fig. 1 depicts the storage technologies that can be combined with the VPP, and their classifications. As shown, there are four categories for a CAES system to handle the heat including adiabatic, diabatic, isothermal, and near isothermal. Also, the hierarchical classification of supercapacitors is shown in the figure.

Also, electric vehicles including both Plug-in Electric Vehicles (PEVs) and Plug-in Hybrid Electric Vehicles (PHEVs) can be considered as energy storage units in VPPs. For example in [14], a VPP considered as the combination of wind power units and electric vehicles. In this study, wind units try to use electric vehicles as a reserve storage unit to handle the uncertain nature of wind generators. As the study confirms, taking advantage of the rapidly growing number of electric vehicles, there is no need for preliminary investment in storage systems. A novel technique for backing up the scheduling of a VPP is suggested in [25]. The purpose of this technique is to reduce the operation costs by considering the extensive integration of Vehicle-to-Grid (V2G). Ref. [26] evaluates the opportunities of using electric vehicles as energy storage units in a VPP. The effects of market procedures on the behavior of market performers and the owners of electric vehicles are simulated in [27]. Ref. [28] presents a review on electric vehicles used in a smart grid. Also, the challenges and problems caused by the large numbers of electric vehicles and investigation of their abilities to interact with the RESs and DR programs are reviewed in [29].

\section{Flexible Loads}

Flexible loads refer to the loads that can adjust their typical consumption patterns in response to variations in the electricity price, or to incentive payments [30]. The flexible or so-called responsive loads are composed of two parts. The first part is a structure which is used for communication between the load and central section. The second part is a control system necessary to regulate the flexible loads' utilization level. The flexible loads' utilization level in a VPP can be changed to meet the certain requirements. These changes can be done through an authorized control command or a kind of price signals called dynamic pricing methods.

The flexibility of dispatchable power plants and intermittent generating units is constrained by practical limits. Therefore, with only using energy production units, the flexibility of the system is restricted $[31,32]$. DR can be used to increase the flexibility of the system. An assessment of the DR flexibility of housing smart appliances is presented in [33]. Ref. [32] declares a comprehensive plan and model of DR and responsive loads. In this study, the flexibility of responsive loads is exploited by means of price-responsive shiftable demand bids in the energy market along with spinning reserve bids in the reserve market.

Different DR definition and categorization are considered through Federal Energy Regulatory Commission (FERC). The state-of-the-art DR definition and categorization are presented thoroughly in [34]. In this study, a comprehensive advantage of DR along with the impacts of DR on electricity prices is considered.

DR needs to be incorporated in a system like a VPP to participate in an electricity market. Ref. [35] assesses the action of incorporating a DR into a VPP trading in a dayahead market and a balancing market. In [36], a functioning process with novel DR programs for a VPP to take part in an energy market is suggested. Also, a method to gain the best offering strategy for a VPP consisting of a wind power producer and a DR in electricity markets is proposed in [15].

The high penetration of both DERs and DR in VPPs requires state-of-the-art technologies for preserving system reliability. The problems caused by high penetration of DERs are reviewed in [37]. Ref. [38] reviews the current application and operation strategy of DR in a smart grid. Ref. [39] presents a review of integrating the DERs and DR in electricity markets.

DR can mitigate the critical load periods and improve the 
reliability of the system. However, implementing the DR needs an accurate demand forecast. The incomplete forecast of demand is the main uncertainty in a system equipped with DR programs. A new DR strategy is offered in [40] which is based on the consumers' submissions of candidate load profiles. Thus, forecasting the price elasticity of demand is not needed. Furthermore, the suggested DR strategy is improved and employed in a framework of the VPP.

\section{OPERATION SYSTEMS OF VPP}

The VPP organizes the dispatchable power plants, intermittent generating units, storage units and DRs by means of an Energy management system (EMS). EMS manages the energy transactions in the VPP through a bidirectional communication. It controls all the units including the nondispatchable and dispatchable power plants, storage units along with responsive loads $[6,41]$. The EMS has a capability of controlling the system for many different objectives such as minimizing costs, minimizing the output pollution, or maximizing the profits. With the aim of these objectives, the EMS is required to receive data related to the units and predict the stochastic information such as renewable generators inputs, the price of energy, probable bottlenecks in the grid and etc.

In many kinds of literature, the modeling of uncertainties is also taken into account such as the uncertainties in nondispatchable renewable recourses, as well as the uncertainties in linear and nonlinear optimization problems. To handle the uncertainty problem, the energy production units, storage units and DRs should be coordinated by the EMS of VPP to guarantee the stability of the VPP. In [42], the energy and reserve are organized at the same time in a VPP, and the Point Estimate Method (PEM) is used for modeling the uncertainties. Ref. [43] offers a stochastic programming model for involving the joint activity of the wind farm hydro system. In this study, in order to effectively handle the lack of wind power prediction, the VPP owner considers its hydro plants as a reserve capacity. The problem is also formulated as a Mixed Integer Linear Programming (MILP) to be solved by available commercial optimization programs. In [44], a probabilistic approach based on PEM is used in a VPP. In this study, the uncertainty of DERs is compensated with the additional reserves. The large-scale integration of DERs is considered thoroughly by industrialized economic dispatch algorithm. Ref. [14] considers a VPP with wind power units and electric vehicles. In this study, wind units use electric vehicles as a storage unit to handle the uncertain nature of wind generators. In [12], a systematic control of a VPP including solar units and responsive demands is explored to handle the uncertain nature of solar generators. The purpose of this work is to propose a flexible load which is able to be changed in a wide range. In order to do so, the power output of the solar units and responsive demands are synchronized. This problem is formulated as a Mixed Integer Programming (MIP) problem. A trading model based on the stochastic programming to maximize the VPP bidding profits in the day-ahead market and balancing market is presented in [45]. The trading model considers the uncertainty of stochastic variables of the VPP. In the direction of moderating the uncertain effects of wind and solar units in a VPP, a robust optimization is presented in [46] to produce a stochastic model considering DR. In [47], a stochastic approach is offered for VPPs considering diverse uncertainties in generation units, electricity consumption and price. The stochastic approach allows them to participate in a day-ahead market. Ref. [48] deliberates the firm capacity provision under a VPP prototype in which the stochastic and intermittent nature of renewable sources is provided. In this study, the decision trees are used in this stochastic optimization problem considering the short-term and longterm firm capacity provision periods. This prototype makes it possible for the VPP to make available reserve capacity and contribute efficiently in electricity markets. Ref. [49] proposes a distributed optimization algorithm for the VPP bi-level optimal dispatch considering uncertain agent number. A VPP model is presented in [50] to expand a heuristic dynamic game theory considering the price uncertainty in addition to the security constraint. The proposed model can efficiently simulate the actions of market performers in a given amount of time to evaluate the economic behavior of the performers.

The bidding strategies offered by a VPP can be organized to fulfill different objectives. For example in $[2,51]$, the bidding problem faced by a VPP is presented with two objectives, participating in day-ahead markets and providing spinning reserve service. The proposed bidding strategy is a non-equilibrium model based on the deterministic price-based unit commitment (PBUC). The bidding strategy takes into account the supply-demand balancing constraint and security constraint. The objectives of [11] are to maximize the selfsupply and market revenue of the CHP-based VPP from the perspective of the VPP in addition to the system operators. Ref. [52] suggests a procedure based on an evolutionary optimization algorithm in order to minimize the operational cost of a VPP which is in charge of DERs in a distribution network. The goal of Ref. [53] is to determine a two-stage operational planning structure for the short-term operation of the VPP. In this study, a stochastic bidding model is suggested for the VPP to maximize the profit from the energy market. Ref. [20] presents a method to find the optimal bidding planning of a VPP comprising a CHP and RES system for the maximum benefit. Ref. [13] studies the optimal bidding approach for a CVPP which includes DERs, battery storage units, and flexible loads. The proposed optimal bidding method is used to maximize the profit along with the expected real-time production and the consumption minimization. In [54], a model of TVPP is proposed to reduce its cost with a non-linear programming considering the constraints of DGs, distribution systems and DR. One of the most important objectives that can be considered in a VPP is the system emission reduction. A multi-agent system is designed in [55] for the emission regulation of the aggregated microgenerators. In this study, the simulations of the operational system are confirmed by using an experimental system. The 
emissions of VPP are regulated to be close to the reference value. In [56], an EMS model for VPPs is proposed to investigate the cost and emission impacts of VPP formation and PHEV penetration for the case study of California.

An arbitrage strategy can be used for VPPs take part in energy and ancillary service such as spinning reserve and reactive power services markets [57]. In [58], the aggregation of DERs as a VPP is studied in a distribution network to allow it to economically take part in joint energy and reserve markets. This approach, which is predicated upon price-based unit commitment method, has considered virtually all the technical data in the proposed model. Ref. [59] develops a VPP to economically offer a conventional energy storage systems through the present network assets along with flexible demands. The cost-effective benefits of the VPP for frequency response services were assessed. In [60], energy and ancillary services is offered to solve the joint management for the following day in view of minimizing the VPP total operation costs. In [61], a probabilistic model is proposed and investigated for optimal day ahead scheduling of electrical and thermal energy resources in a VPP by simultaneously scheduling the energy and reserve in the presence of energy storage devices and demand response resources.

\section{CONCLUSION}

Generally, through the VPP concept, each DER has the opportunity to participate in the whole electricity markets. A VPP can obtain the precise information about the market for its optimization problem such that the DERs in the VPP can achieve the maximum capacity. The most important financial advantages of the VPP for DER owners are the maximum profit from the electricity markets and reduced monetary risk. In this paper, the essential elements of the VPP including dispatchable power plants and intermittent generating units, flexible loads and storage units have been reviewed in a comprehensive way. The fundamental features of the two VPP categories, namely CVPP and TVPP, have been explained. Moreover, the literature related to CHP-based VPP, VPP components and modeling, VPP with DR and VPP bidding strategy has been considered in this paper.

\section{REFERENCES}

[1] P. Djapic, C. Ramsay, D. Pudjianto, G. Strbac, J. Mutale, N. Jenkins, et al., "Taking an active approach," Power and Energy Magazine, IEEE, vol. 5, pp. 68-77, 2007.

[2] E. Mashhour and S. M. Moghaddas-Tafreshi, "Bidding strategy of virtual power plant for participating in energy and spinning reserve markets-Part I: Problem formulation," Power Systems, IEEE Transactions on, vol. 26, pp. 949-956, 2011.

[3] A. Dauensteiner, "European virtual fuel cell power plant," Management Summary Report, 2007.

[4] D. Pudjianto, C. Ramsay, G. Strbac, and M. Durstewitz, "The virtual power plant: Enabling integration of distributed generation and demand," FENIX Bulletin, vol. 2, pp. 10-16, 2008.

[5] D. Pudjianto, C. Ramsay, and G. Strbac, "Virtual power plant and system integration of distributed energy resources," Renewable power generation, IET, vol. 1, pp. 10-16, 2007.

[6] H. Saboori, M. Mohammadi, and R. Taghe, "Virtual power plant (vpp), definition, concept, components and types," in Power and
Energy Engineering Conference (APPEEC), 2011 Asia-Pacific, 2011, pp. 1-4.

[7] A. Tascikaraoglu, O. Erdinc, M. Uzunoglu, and A. Karakas, "An adaptive load dispatching and forecasting strategy for a virtual power plant including renewable energy conversion units," Applied Energy, vol. 119, pp. 445-453, 2014.

[8] T. Sousa, H. Morais, Z. Vale, and R. Castro, "A multi-objective optimization of the active and reactive resource scheduling at a distribution level in a smart grid context," Energy, vol. 85, pp. 236250, 2015

[9] H. Pandžić, I. Kuzle, and T. Capuder, "Virtual power plant midterm dispatch optimization," Applied Energy, vol. 101, pp. 134$141,2013$.

[10] H. Pandžić, J. M. Morales, A. J. Conejo, and I. Kuzle, "Offering model for a virtual power plant based on stochastic programming," Applied Energy, vol. 105, pp. 282-292, 2013.

[11] K. Dietrich, J. M. Latorre, L. Olmos, and A. Ramos, "Modelling and assessing the impacts of self supply and market-revenue driven Virtual Power Plants," Electric Power Systems Research, vol. 119, pp. 462-470, 2015

[12] Y. Liu, H. Xin, Z. Wang, and D. Gan, "Control of virtual power plant in microgrids: a coordinated approach based on photovoltaic systems and controllable loads," Generation, Transmission \& Distribution, IET, vol. 9, pp. 921-928, 2015.

[13] E. G. Kardakos, C. K. Simoglou, and A. G. Bakirtzis, "Optimal Offering Strategy of a Virtual Power Plant: A Stochastic Bi-Level Approach," 2015.

[14] M. Vasirani, R. Kota, R. L. Cavalcante, S. Ossowski, and N. R. Jennings, "An agent-based approach to virtual power plants of wind power generators and electric vehicles," Smart Grid, IEEE Transactions on, vol. 4, pp. 1314-1322, 2013.

[15] J. Aghaei, M. Barani, M. Shafie-khah, A. A. Sanchez de la Nieta, and J. P. Catalao, "Risk-Constrained Offering Strategy for Aggregated Hybrid Power Plant Including Wind Power Producer and Demand Response Provider."

[16] S. V. Papaefthymiou and S. A. Papathanassiou, "Optimum sizing of wind-pumped-storage hybrid power stations in island systems," Renewable Energy, vol. 64, pp. 187-196, 2014.

[17] J. Zapata, J. Vandewalle, and W. D'haeseleer, "A comparative study of imbalance reduction strategies for virtual power plant operation," Applied Thermal Engineering, vol. 71, pp. 847-857, 2014.

[18] B. Wille-Haussmann, T. Erge, and C. Wittwer, "Decentralised optimisation of cogeneration in virtual power plants," Solar Energy, vol. 84, pp. 604-611, 2010.

[19] C. Schulz, G. Röder, and M. Kurrat, "Virtual Power Plants with combined heat and power micro-units," in Future Power Systems, 2005 International Conference on, 2005, pp. 5 pp.-5.

[20] J. Z. Riveros, K. Bruninx, K. Poncelet, and W. D'haeseleer, "Bidding strategies for virtual power plants considering CHPs and intermittent renewables," Energy Conversion and Management, vol. 103, pp. 408-418, 2015.

[21] M. Alipour, B. Mohammadi-Ivatloo, and K. Zare, "Stochastic riskconstrained short-term scheduling of industrial cogeneration systems in the presence of demand response programs," Applied Energy, vol. 136, pp. 393-404, 2014.

[22] T. Sowa, S. Krengel, S. Koopmann, and J. Nowak, "Multi-criteria operation strategies of power-to-heat-Systems in virtual power plants with a high penetration of renewable energies," Energy Procedia, vol. 46, pp. 237-245, 2014.

[23] H. Zhao, Q. Wu, S. Hu, H. Xu, and C. N. Rasmussen, "Review of energy storage system for wind power integration support," Applied Energy, vol. 137, pp. 545-553, 2015.

[24] S. Rehman, L. M. Al-Hadhrami, and M. M. Alam, "Pumped hydro energy storage system: a technological review," Renewable and Sustainable Energy Reviews, vol. 44, pp. 586-598, 2015.

[25] T. Sousa, H. Morais, J. Soares, and Z. Vale, "Day-ahead resource scheduling in smart grids considering vehicle-to-grid and network constraints," Applied Energy, vol. 96, pp. 183-193, 2012.

M. Musio, P. Lombardi, and A. Damiano, "Vehicles to grid (V2G) concept applied to a virtual power plant structure," in Electrical Machines (ICEM), 2010 XIX International Conference on, 2010, pp. 1-6. 
[27] M. Shafie-khah, M. P. Moghaddam, M. K. Sheikh-El-Eslami, and M. Rahmani-Andebili, "Modeling of interactions between market regulations and behavior of plug-in electric vehicle aggregators in a virtual power market environment," Energy, vol. 40, pp. 139-150, 2012.

[28] F. Mwasilu, J. J. Justo, E.-K. Kim, T. D. Do, and J.-W. Jung, "Electric vehicles and smart grid interaction: A review on vehicle to grid and renewable energy sources integration," Renewable and Sustainable Energy Reviews, vol. 34, pp. 501-516, 2014.

[29] J. Aghaei, A. E. Nezhad, A. Rabiee, and E. Rahimi, "Contribution of Plug-in Hybrid Electric Vehicles in power system uncertainty management," Renewable and Sustainable Energy Reviews, vol. 59, pp. 450-458, 2016.

[30] P. Siano, "Demand response and smart grids-A survey," Renewable and Sustainable Energy Reviews, vol. 30, pp. 461-478, 2014.

[31] Y. T. Tan and D. S. Kirschen, "Co-optimization of energy and reserve in electricity markets with demand-side participation in reserve services," in Power Systems Conference and Exposition, 2006. PSCE'06. 2006 IEEE PES, 2006, pp. 1182-1189.

[32] G. Liu and K. Tomsovic, "A full demand response model in cooptimized energy and reserve market," Electric Power Systems Research, vol. 111, pp. 62-70, 2014.

[33] R. D'hulst, W. Labeeuw, B. Beusen, S. Claessens, G. Deconinck, and $\mathrm{K}$. Vanthournout, "Demand response flexibility and flexibility potential of residential smart appliances: Experiences from large pilot test in Belgium," Applied Energy, vol. 155, pp. 79-90, 2015.

[34] J. Aghaei and M.-I. Alizadeh, "Demand response in smart electricity grids equipped with renewable energy sources: A review," Renewable and Sustainable Energy Reviews, vol. 18, pp. 64-72, 2013.

[35] S. R. Dabbagh and M. K. Sheikh-El-Eslami, "Participation of demand response resources through virtual power plant: A decision framework under uncertainty," in Environment and Electrical Engineering (EEEIC), 2015 IEEE 15th International Conference on, 2015, pp. 2045-2049.

[36] A. G. Zamani, A. Zakariazadeh, S. Jadid, and A. Kazemi, "Operational scheduling of Virtual Power Plants in the presence of energy storages and demand response programs for participating in the energy market," in Electrical Power Distribution Networks Conference (EPDC), 2015 20th Conference on, 2015, pp. 218-222.

[37] M. A. Zehir, A. Batman, and M. Bagriyanik, "Review and comparison of demand response options for more effective use of renewable energy at consumer level," Renewable and Sustainable Energy Reviews, vol. 56, pp. 631-642, 2016.

[38] F. Shariatzadeh, P. Mandal, and A. K. Srivastava, "Demand response for sustainable energy systems: A review, application and implementation strategy," Renewable and Sustainable Energy Reviews, vol. 45, pp. 343-350, 2015.

[39] Q. Wang, C. Zhang, Y. Ding, G. Xydis, J. Wang, and J. Østergaard, "Review of real-time electricity markets for integrating distributed energy resources and demand response," Applied Energy, vol. 138, pp. 695-706, 2015.

[40] A. Mnatsakanyan and S. W. Kennedy, "A novel demand response model with an application for a virtual power plant," Smart Grid, IEEE Transactions on, vol. 6, pp. 230-237, 2015.

[41] M. Braun and P. Strauss, "A review on aggregation approaches of controllable distributed energy units in electrical power systems," International Journal of Distributed Energy Resources, vol. 4, pp. 297-319, 2008.

[42] A. G. Zamani, A. Zakariazadeh, and S. Jadid, "Day-ahead resource scheduling of a renewable energy based virtual power plant," Applied Energy, vol. 169, pp. 324-340, 2016.

[43] I. G. Moghaddam, M. Nick, F. Fallahi, M. Sanei, and S. Mortazavi, "Risk-averse profit-based optimal operation strategy of a combined wind farm-cascade hydro system in an electricity market," Renewable energy, vol. 55, pp. 252-259, 2013.

[44] M. Peik-Herfeh, H. Seifi, and M. Sheikh-El-Eslami, "Decision making of a virtual power plant under uncertainties for bidding in a day-ahead market using point estimate method," International Journal of Electrical Power \& Energy Systems, vol. 44, pp. 88-98, 2013.
[45] C. Dong, X. Ai, S. Guo, K. Wang, Y. Liu, and L. Li, "A study on short-term trading and optimal operation strategy for virtual power plant," in 2015 5th International Conference on Electric Utility Deregulation and Restructuring and Power Technologies (DRPT), 2015, pp. 2672-2677.

[46] L. Ju, Z. Tan, J. Yuan, Q. Tan, H. Li, and F. Dong, "A bi-level stochastic scheduling optimization model for a virtual power plant connected to a wind-photovoltaic-energy storage system considering the uncertainty and demand response," Applied Energy, vol. 171, pp. 184-199, 2016.

[47] M. A. Rostami and M. Raoofat, "Optimal operating strategy of virtual power plant considering plug-in hybrid electric vehicles load," International Transactions on Electrical Energy Systems. 2015.

[48] P. Moutis and N. D. Hatziargyriou, "Decision trees aided scheduling for firm power capacity provision by virtual power plants," International Journal of Electrical Power \& Energy Systems, vol. 63, pp. 730-739, 2014.

[49] J. Yu, Y. Jiao, X. Wang, J. Cao, and S. Fei, "Bi-level optimal dispatch in the Virtual Power Plant considering uncertain agents number," Neurocomputing, vol. 167, pp. 551-557, 2015.

[50] M. Shafie-Khah, M. P. Moghaddam, and M. K. Sheikh-El-Eslami, "Development of a virtual power market model to investigate strategic and collusive behavior of market players," Energy Policy, vol. 61, pp. 717-728, 2013.

[51] E. Mashhour and S. M. Moghaddas-Tafreshi, "Bidding strategy of virtual power plant for participating in energy and spinning reserve markets-Part II: Numerical analysis," Power Systems, IEEE Transactions on, vol. 26, pp. 957-964, 2011.

[52] P. Faria, J. Soares, Z. Vale, H. Morais, and T. Sousa, "Modified particle swarm optimization applied to integrated demand response and DG resources scheduling," Smart Grid, IEEE Transactions on, vol. 4, pp. 606-616, 2013.

[53] F. Luo, Z. Y. Dong, K. Meng, J. Qiu, J. Yang, and K. P. Wong, "Short-term operational planning framework for virtual power plants with high renewable penetrations," IET Renewable Power Generation, 2016.

[54] H. Nezamabadi and V. Vahidinasab, "Two stage decision making of technical virtual power plants in electricity market via NashSFE equilibrium," in Smart Grid Congress and Fair (ICSG), 2015 3rd International Istanbul, 2015, pp. 1-5.

[55] S. Skarvelis-Kazakos, E. Rikos, E. Kolentini, L. M. Cipcigan, and N. Jenkins, "Implementing agent-based emissions trading for controlling Virtual Power Plant emissions," Electric Power Systems Research, vol. 102, pp. 1-7, 2013.

[56] O. Arslan and O. E. Karasan, "Cost and emission impacts of virtual power plant formation in plug-in hybrid electric vehicle penetrated networks," Energy, vol. 60, pp. 116-124, 2013.

[57] H. Nezamabadi and M. S. Nazar, "Arbitrage strategy of virtual power plants in energy, spinning reserve and reactive power markets," IET Generation, Transmission \& Distribution, vol. 10, pp. $750-763,2016$.

[58] P. Karimyan, M. Abedi, S. H. Hosseinian, and R. Khatami, "Stochastic approach to represent distributed energy resources in the form of a virtual power plant in energy and reserve markets," IET Generation, Transmission \& Distribution, vol. 10, pp. 1792$1804,2016$.

[59] M. Cheng, S. S. Sami, and J. Wu, "Benefits of using virtual energy storage system for power system frequency response," Applied Energy, 2016.

[60] T. Sousa, T. Soares, H. Morais, R. Castro, and Z. Vale, "Simulated annealing to handle energy and ancillary services joint management considering electric vehicles," Electric Power Systems Research, vol. 136, pp. 383-397, 2016.

[61] A. G. Zamani, A. Zakariazadeh, S. Jadid, and A. Kazemi, "Stochastic operational scheduling of distributed energy resources in a large scale virtual power plant," International Journal of Electrical Power \& Energy Systems, vol. 82, pp. 608-620, 2016. 